\title{
Understanding legitimate teacher authority in a cross-cultural teaching context: pre-service Chinese language teachers undertaking teaching practicum in international schools in Hong Kong
}

Chun Lai ${ }^{\mathrm{a} *}$, Mingyue $\mathrm{Gu}^{\mathrm{b}}$ and Jingjing $\mathrm{Hu}^{\mathrm{a}}$

${ }^{a}$ Faculty of Education, The University of Hong Kong, Hong Kong; ${ }^{b}$ Faculty of Education, The Chinese University of Hong Kong, Hong Kong

(Received 2 January 2015; accepted 20 May 2015)

Legitimate teacher authority is fundamental to effective teaching, but is often a thorny issue that teachers need to grapple with when teaching in cross-cultural teaching contexts. By interviewing 18 pre-service Chinese language teachers on their understanding of legitimate teacher authority throughout teaching practicum at international schools in Hong Kong, this study revealed that the teachers changed their perception about the essentiality and the nature of the pedagogical and interpersonal components of legitimate teacher authority. They developed a more nuanced and balanced understanding about legitimate teacher authority over time. However, their abilities in reaching the balance were constrained by their cultural knowledge and skills in achieving positive interpersonal dynamics when implementing student-centred pedagogies.

Keywords: teacher authority; pre-service teacher education; teaching practicum; cross-cultural teaching

\section{Introduction}

Becoming a teacher involves defining and redefining one's identity in a 'socially legitimated' manner in relation to the teaching context (Coldron and Smith 1999). Teachers are constantly constructing "their own ideas of "how to be", "how to act" and "how to understand" their work and their place in society" (Beauchamp and Thomas 2009; Sachs 2005, 15). In particular, pre-service teachers are at the initial learning-to-teach stage, and their perceptions of what it means to teach undergo active construction and reconstruction and are in constant flux (Izadinia 2013; Trent 2010). Examining their socialisation process with respect to various aspects of teaching would provide essential information on what teacher educators could do to shape smoothly and positively the process of learning to teach (Thomas and Beauchamp 2011).

Pre-service teachers' socialisation involves negotiating various tensions or dilemmas between 'personal subjectivities or ideologies and their professional selves' (Pillen, Beijaard, and Brok 2013, 661-662). In cross-cultural teaching contexts, pre-service teachers are likely to face additional tensions arising from ideologi-

*Corresponding author. Email: laichun@hku.hk 
cal differences between their ethnic cultures and the dominant culture of the teaching context, including different expectations regarding the cultural norms of education, the role of teachers and students, competing pedagogical storylines and 'cultures of instruction' (Hall Haley and Ferro 2011; McCluskey 2012; Subedi 2008). As a result of these tensions, pre-service teachers in cross-border and cross-cultural teaching contexts have to negotiate cultural identity and professional identity (Lai 2013; Subedi 2008), different cultural approaches to curriculum and instruction (Hanson 2013; Scotland 2014; $\mathrm{Xu} 2012$ ), and different expectations regarding legitimate teacher-ity and class discipline (Hanson 2013; Liu 2012; Xu 2012; Zhou 2014).

Legitimate teacher authority and class discipline are essential to student-teacher relationships and to overall teaching effectiveness, but they are often tensions that teachers of Asian backgrounds need to grapple with when teaching in schools with a predominantly Western culture (Gao 2010; Hall Haley and Ferro 2011; Hanson 2013). Failure to reconcile themselves to the cultural differences in legitimate teacher authority may lead not only to ineffective teaching, but also attrition of beginning teachers (Romig 2009). Thus, this study aimed to understand how a group of pre-service teachers of Chinese ethnic and educational backgrounds perceived legitimate teacher authority during their teaching practicum at international schools in Hong Kong. Insights into their developing understanding of this key concept was hoped to shed light on teachers' development of legitimate teacher authority in different contexts (Graca, Calheiros, and Barata 2013; Pace and Hemmings 2007) and provide insights into how pre-service teachers could be supported in 'potentially identity threatening transitions' (Scotland 2014, 39).

\section{Research background}

\section{Teacher authority}

'Authority' refers to the establishment of 'a communicative relationship, however broadly defined, between the givers and the receivers of orders' (Hearn 2012, 23). In the classroom context, this communicative relationship, authoritarian or friendly, is aimed at exerting influence over students' thoughts and actions (Elliott 2009; Pellegrino 2010). Teacher authority is important in maintaining a functional class that enhances students' learning outcomes (Koutrouba, Baxevanou, and Koutroumpas 2012; Richmond and McCroskey 1984) and is fundamental to effective teaching (Pellegrino 2010; Roberson 2014). Current literature on teacher authority has reached the following understandings:

(1) Teacher authority is a multidimensional concept and can be asserted in various forms (Elliott and Stemler 2008; Macleod, MacAllister, and Pirrie 2012). Pace and Hemmings (2007) categorised teacher authority into four types: formal authority, professional authority, charismatic authority and bureaucratic (legal-rational) authority. Formal authority refers to authority granted by the shared norms and cultural mores regarding the social roles of teachers and students. Professional authority refers to authority established through gaining students' acceptance of teachers' professional knowledge and their ability to deliver it to the benefit of students. Charismatic authority refers to authority based on teachers' personal dispositions and charisma. Bureaucratic authority emphasises teacher authority as defined by classroom rules, school 
discipline policies and student progress monitoring mechanisms. Macleod, MacAllister, and Pirrie (2012) further developed the model, expanding on bureaucratic authority. In their framework of teacher authority, there are five forms of teacher authority: legitimate authority, which corresponds with formal authority; competent authority, which corresponds with professional authority; personal authority, which corresponds with charismatic authority; coercive authority, which refers to authority established through discipline approaches, such as threat and punishment; and authority by inducement, which refers to authority established through issuing rewards. Thus, despite the different labels, teacher authority involves sociocultural, institutional and personal (both interpersonal and pedagogical) dimensions.

(2) Teacher authority is relational. Teacher authority originates from the communicative relationships between teachers and students, and thus it is interactional and dynamic (Nathan 2012; Roberson 2014). Teacher authority is a two-way social relationship that relies not only on teachers' dispositions and capacities to influence students into behaving in certain ways, but also on students' perceptions and acceptance of teachers' power (Hearn 2012; Li 2012; Macleod, MacAllister, and Pirrie 2012). Teachers will hold legitimate authority if and only if students 'accept its legitimacy and consent to do what is required of them' (Elliott 2009, 198). Oyler (1996) argued that teacher authority, due to its relational nature, needs to be shared among the students and teachers. Nathan (2012) further highlighted that teacher authority, no matter if professional/expertise based or rule based, cannot stand without being actively aligned with students' expectations and securing students' consensual acceptance and involvement. Thus, one form of teacher authority that works well in one context may turn out to be ineffective in another context.

(3) Teacher authority needs to be earned and negotiated. It is generally agreed that the changing societal views about the nature and exercise of authority have greatly weakened the legitimacy and influence of traditional authority, especially in Western societies (Elliot and Stemler 2008; Pace and Hemmings 2007). The de jure authority, authority conferred simply by virtue of being a teacher, needs to give way quickly to a legitimate authority earned and negotiated by teachers through building up consensual and cooperative relationships with students if teachers want to be effective in their classrooms (Elliott 2009; Harjunen 2011).

Thus, teachers may have various forms of teacher authority in hand for disposal, and they need to act on and negotiate different forms of authority relationship in response to the sociocultural realities of the particular teaching contexts they are placed in so as to establish legitimate teacher authority in their teaching contexts.

\section{The development of legitimate teacher authority}

Legitimate teacher authority is the form of teacher authority that requires the students' consensual acceptance of teachers' power and cooperation in, and consent to do, what is required of them in a particular teaching context. To establish legitimate teacher authority, teachers need to act on their knowledge and skills in both the academic and social domains (Pace and Hemmings 2007; Roberson 2014). Teachers 
need to prove their expertise in both domains and provide evidence of both legitimate pedagogical authority and legitimate interpersonal authority (Elliott 2009; Harjunen 2011; Pace and Hemmings 2007), namely both the subject and pedagogical knowledge and the skills in relation to classroom interpersonal dynamics (Elliott and Stemler 2008). Roberson (2014) further argued that legitimate teacher authority relies on the positive interaction between the pedagogical and interpersonal domains. Her study on students' and teachers' perceptions and practices of effective teaching showed that students were willing to acknowledge legitimate teacher authority: (1) when the teachers cared about students' interests and learning difficulties and showed the care in planning and facilitating relevant and effective learning experience; (2) when the teachers were willing to give respect to students unconditionally and treat them as equals, respecting their thoughts and opinions; and (3) when the teachers proved their trustworthiness through being open and candid about their subject and pedagogical expertise and being fair and consistent in their interactions with the students.

The view of establishing legitimate teacher authority through creating pedagogical communities that take into consideration students' psychosocial needs is echoed among different scholars (Koutrouba, Baxevanou, and Koutroumpas 2012; Nathan 2012). Smith and Matusov (2011) referred to this as 'relational pedagogy based on mutuality and reciprocity', whereby genuine dialogues between teacher and students are created and students' interests are reflected and respected in the dialogues. Despite these studies that revealed some attributes of legitimate teacher authority, there is still limited understanding of how teachers develop legitimate teacher authority in different contexts (Nathan 2012; Roberson 2014).

At the same time, scholars are pointing out that legitimate teacher authority is not universal, but rather tempered by social cultural and contextual factors (Elliot and Stemler 2008; Wong 2014). Pace and Hemmings (2007) emphasised that legitimate teacher authority is value laden and culturally sensitive. In different sociocultural and instructional contexts, different forms of teacher authority might be perceived differently and have differential effects since 'different assumptions and values that comprise the hidden structures of schooling result in different views on what constitutes ideal authority relations in schools' (Macleod, MacAllister, and Pirrie 2012, 495). Researchers have shown that students in different cultures value different authority attributes (Kim 1998; Laupa and Tse 2005).

Given the cultural relativity of legitimate teacher authority, teachers in cross-cultural teaching contexts may encounter greater tensions in earning legitimate teacher authority than teachers who are teaching in their own cultural contexts. Moreover, the authority relationship negotiation may be further complicated by their lack of relational history with the students (Roberson 2014). Considering the exponential increase of teachers engaging in cross-cultural teaching, it is necessary to understand how teachers come to terms with legitimate teacher authority in cross-cultural teaching contexts, a particular setting of legitimate teacher authority development. This particular study focused on the changing perceptions of legitimate teacher authority among a group of teachers of ethnic Chinese backgrounds teaching at schools dominated by Western cultures. 


\section{Legitimate teacher authority for Chinese teachers in cross-cultural teaching contexts}

Studies have found large ideological and social normative differences among the eastern and Western cultures, which shapes different social expectation on legitimate teacher authority. The comparison of the socially expected legitimate teacher authority in Chinese and American cultures shows some fundamental differences. Teachers in the United States are expected to behave in a more impersonal manner in fulfilling institutional roles and upholding impartiality, and their roles are to support students' development and encourage students to initiate communication and voice intellectual disagreement. In contrast, teachers in China are regarded as experts in the subject areas, role models and moral agents, and are expected to be respected by students and parents both inside and outside the classroom as authority figures. Intel-

15 lectual disagreement and student-initiated free expression and thinking are regarded as disruptive behaviours and a challenge to teacher authority in this context (Gao 2010; Hall Haley and Ferro 2011; Hanson 2013). Respect for teachers also takes on different connotations in Confucian and Western contexts: respect for teachers in the Western contexts is based more on equality and cooperation, whereas respect for 20 teachers in the Confucian context focuses more on hierarchical deference, structure, order and unconditional obedience (Gao 2010; Liu 2012; Nguyen 2008).

Consequently, teachers of Chinese ethnic origins have reported encountering various challenges to establishing legitimate teacher authority when teaching in Western contexts. Studies have shown that teachers are shocked by students' freedom of expression and movement in the classroom and their rebellious manner (Gao 2010; Romig 2009; Zhou 2014), and they struggle with different cultural interpretations of respect and discipline strategies (Hanson 2013; Liu 2012; Zhou 2014). They find that their assumed role of moral agents is not appreciated by students (Liu 2012), and they have a hard time establishing a welll-balanced boundary between teacher and students (Gao 2010).

Given the challenges Chinese teachers encounter in establishing legitimate teacher authority in cross-cultural teaching contexts and the paucity of research on teachers' development of legitimate teacher authority, this study set out to fill in the current research gap by examining how Chinese teachers came to terms with legitimate teacher authority while facing the enormous challenges in their cross-cultural teaching contexts. It focused on unravelling a group of pre-service Chinese language teachers' developing understanding of legitimate teacher authority during their teaching practicum. Specifically, the study examined the changes in their perceptions of legitimate teacher authority at different stages of their teaching practicum. Understanding changes in their perceptions of legitimate teacher authority over time can shed light on how pre-service teachers can be supported in coping with the challenges in cross-cultural teaching while learning to teach. The following research question was addressed: 'How do the pre-service Chinese language teachers from mainland China perceive legitimate teacher authority during teaching practicum at international schools in Hong Kong?'

\section{Research method}

\section{Research background}

This study was conducted in Hong Kong, a plurilingual and multicultural society with around $6.4 \%$ non-ethnic Chinese population. Hong Kong had been a colony of 
the Great Britain for over 150 years. Given Hong Kong's predominant ethnic Chinese population and its colonial history, the educational culture in Hong Kong is shaped by both Confucian tradition and Western influences, and its educational norms are different from those of mainland China (Author 2013; Wong 2014).

International schools in Hong Kong are self-financing private schools and usually adopt the national curriculum of different countries or an international curriculum. International schools in Hong Kong were established mainly to satisfy the educational needs of expatriate students, and only about $14 \%$ of students in international schools are local students (Woo 2014). The Hong Kong Government defines international schools as schools that 'are operated with curricula designed for the needs of a particular cultural, racial or linguistic group or for students wishing to pursue their studies overseas' (HKED 1995, 4). Thus, international schools are heavily dominated by Western cultures, and Western teaching staff predominate.

\section{Participants}

The participants were recruited from a Master of Education programme at a university in Hong Kong. The study was announced to the students on behalf of the second author, who was not affiliated to the programme. Eighteen out of 23 pre-service Chinese-language teachers on this programme volunteered to participate in the study. They were all ethnic Chinese who had their K-12 education in mainland China. They were all female, which reflected the predominance of female Chinese-language teachers at Hong Kong international schools. The majority of the participants were fresh graduates from Bachelor programmes in Chinese language and literature or teaching Chinese as a foreign language from different universities in mainland China. They had come to Hong Kong to study on this one-year full-time teacher training course.

The programme prepared teachers for teaching Chinese as a second language, and there was a heavy teaching practicum component. Each student was attached to an international secondary school with a school mentor from the Chinese language panel designated by the school. The teaching practicum schools had a mixed student population of ethnic Chinese students, mostly from expatriate families, and students from different cultural backgrounds and represented 30-50 nationalities. The students started their school attachment phase in the first semester, during which time they went to their teaching practicum schools for class observations at least one day per week. In the second semester, they started their main teaching practice phase with six weeks' blocked teaching practice, during which time they stayed at the schools in the daytime and attended classes at the university in the evening. This study was based on the self-reports of the group of female per-service Chinese-language teachers during their two-stage teaching practicum where they had their first encounter with cross-cultural teaching.

\section{Data collection and analysis}

Individual semi-structured interviews were conducted with each participant to elicit their views and reflections on their cross-cultural teaching experience at international schools. Three rounds of interviews were conducted with each participant: prior to the commencement of the school experience; at the end of the school attachment phase; and at the end of their main teaching practice. The first interview mainly 
focused on their motivation to teach and their perceptions of teaching and teacherstudent relationships. The second and the third interviews engaged the participants in reflecting on their lived experiences during their school attachment and main teaching practice, respectively, eliciting what they had learned from the experience, their perceptions of teaching and teacher-student relationships, and their interaction with the mentors. The first interview was conducted by the second 3 who was not affiliated with the programme, and the second and the third interview were conducted by the first author when her teaching relationship with the participants was over. The interviews were conducted in the participants' native language, Mandarin. Each interview lasted around 30-40 min, and constant elaboration and clarification questions were asked to obtain in-depth insights and to confirm the intended mean-

15 ing of the participants.

All the interviews were transcribed verbatim in Chinese and double-checked for accuracy. The interview data were read line by line, and meaningful segments of text that struck the researchers as interesting or important to the study were coded. Invivo codes were used in the initial coding. Focused coding was conducted, whereby

20 similar codes were aggregated into larger analytic categories that were informed by both the research literature and the database (Bogdan and Biklen 2003). Annotations and memos were used during the data analyses to record immediate comments and reflexive thinking on the data to assist the coding process. For instance, the phrases and segments that captured the participants' perceptions of the elements critical to 25 teacher authority were first coded using the interviewees' original words. For example, phrases, such as, 'personal value in delivering knowledge and helping others grow', 'needs first of all to have strong disciplinary knowledge' and 'a useful teacher who not only teaches students knowledge but also helps them to succeed in exams', were combined under the analytic category of 'emphasise disciplinary

30 knowledge and teaching skills'. The initial coding of analytic categories was compared across interviewees to search for repeating ideas to saturate categories with repeated supporting evidence and for cross validation of the categories that emerged. For each category, segments of the texts that illustrated the same analytic category were pooled across individuals. Pseudonyms are used when presenting the results.

\section{Results}

The interview data indicated that the participants went through a process of redefining legitimate teacher authority at different stages of their pre-service teacher training: prior to their school experience, during their school attachment and during their main teaching practice.

$40 \quad$ Changing perceptions of the pedagogical and interpersonal components of legitimate teacher authority

Prior to the school experience, the majority of the participants felt that pedagogical authority was critical to their success at the teaching practicum. Although they did acknowledge that it was important to establish good student-teacher relationships, they did not regard interpersonal relationship as a major obstacle to their success. They took pedagogical authority as the key to gaining legitimacy at the schools. When asked what they needed to work on the most in order to become a successful 
teacher, the majority of them listed strengthening disciplinary knowledge and teaching techniques as the priority (Appendix 1):

I should have very strong foundations in disciplinary knowledge. I always worry that what I know is not enough. (Bing)

First, I need to improve my teaching techniques; second, I don't have sufficient discipline knowledge; third, I have never taught K-12 students before. The situation might be different. I need to learn how to interact with students. (Li)

However, during the school attachment phase, the participants were shocked to find that formal/traditional authority was not something they could take for granted; as Li commented: 'students do not respect you as a teacher, neither do they follow your instructions unconditionally'. The participants complained of students treating them as 'invisible' and not greeting them on the campus, despite knowing them as teachers. They also felt students lacked respect for their mentor teachers in the classroom, frequently observing students 'sitting on the windowsill or lying on the floor', 'walking around without raising their hands' and 'chattering all the time in class'. Yan was shocked to find that some students sat at the back of the classroom, totally ignoring her mentor, and one of them even frequently slept through her mentor's class. Jun even heard some students in her mentor's class telling her mentor directly that they did not like Jun's class, which she found very disturbing. Such observations made the participants perceive that building positive student-teacher relationships was much more essential in the teaching context than they used to believe:

I used to think that if I can teach well, then I'm a good teacher. Now I realize that personal charisma is very important. You need to know how to interact with the students, what they need, what they like. Only when you have close relationship with them will they be willing to cooperate in your class. (Jing)

They found that successful teachers were often those who knew how to build positive relationships with the students. Some participants commented that building positive student-teacher relationships was critical to the smooth running of the class.

I used to believe that Chinese language teaching is all about teaching the language. As a teacher, I teach students whatever they want to learn. Now I finally understand what it means to teach. You not only teach them language, but also need to handle teacherstudent relationship well. Otherwise, your teaching won't go well. (Fan)

\section{Changing perceptions of legitimate pedagogical authority}

Prior to the school experience, 16 participants reported that the critical traits for being a successful teacher included possessing strong disciplinary knowledge and having techniques in delivering the knowledge.

I think an ideal teacher needs to find enjoyment and personal value in delivering knowledge and helping others grow. (Jun)

A successful teacher needs first of all to have strong disciplinary knowledge, and then needs to have personal charisma that attracts students' to his or her classes. (Mei)

I want to become a useful teacher, who not only teaches students knowledge but also helps them to succeed in exams. (Juan) 
However, the stress on strong disciplinary knowledge started to fade after the participants started their school practice. At the school attachment period, the participants realised that impressing students with strong disciplinary knowledge may not necessarily guarantee legitimate teacher authority. They found that having strong disciplinary knowledge could 'no longer help teachers to position themselves as successful teachers' (Quan), and that students did not expect teachers to be the 'knowers', who had the answers to all of their questions either. The participants observed that legitimate teacher authority could be successfully asserted through making teaching appealing to students:

I found that the key to asserting legitimate teacher authority is to make your class interesting. Students don't care about adults talking about long-term goals and future development, but if you make your class fun and attractive, the students will naturally be willing to learn with you. (Juan)

This understanding came partly from their observation that students were very outgoing and participative. They found that 'students did not wait for teachers to call

20 their names'; rather, they were very active and 'eager to share their thoughts and present their work'. Yang commented that although they had discussed during university lectures the characteristics of international school students being active, she 'got a real sense of' how active these students could be once she was in the school:

I saw many students volunteering to answer questions. Almost the whole class raised hands when a question was asked. This is quite different from what I have experienced, which is usually teacher-centered and not much chance is given for students to raise questions and talk. (Xin)

This observation made the participants feel encouraged to make use of the students' active disposition, and feel pressured to adopt student-centred approaches:

30 The students in the international schools in general are quite active and like to get involved. If we could make good use of these student characteristics, it would benefit teaching. Engaging them in activities is a good way. (Yang)

This understanding was reinforced by their observation that many students in the international schools did not have strong motivation to learn Chinese. They found that some students 'were unwilling to do homework assigned by the teachers', and 'studied other subjects in the Chinese class or even slept through the classes'. Observing the low motivation among the students, the participants felt that making classes interesting was critical to legitimate teacher authority:

I found that in international schools, if you don't design activities, you can't engage the students. They won't listen to you. You need to design more activities and change activities regularly. Only then would they be more likely to participate. (Xuan)

Very few students have self-discipline and strong motivation to learn Chinese. I feel that it's useless to motivate them to study by stressing how important Chinese is. You can't force them to learn. How to raise their interest in Chinese and engage them actively in class is quite critical and challenging as well. (Juan)

Despite the predominant view that legitimate teacher authority should be asserted through student-centred approaches, Jun did voice some concern over the use of such approaches:

It's hard to control the students already. They already have discipline problems. I'm concerned of losing control of the class if I engage them with activities. 


\section{0 C. Lai et al.}

At the main teaching practice phase, the participants found that student-centred approaches did help secure students' attention and involvement and help them assert legitimate teacher authority. They verified that the students did not like listening to them lecturing and preferred hands-on and inquiry activities. Xue reflected that she was quite worried about managing the active students when it was her turn to teach. She designed hands-on activities to engage her students, and found that 'students were highly motivated and also learned the things they were expected to learn', and that students' attentiveness and cooperation level were much higher than previous lessons, in which she had taught in a teacher-directed instruction manner. Thus, she recognised student-centred approaches as the legitimate pedagogical authority. Fan observed that,

If I did activities, the students were willing to participate and follow the instructions. When there were no activities, they felt bored and digressed to attend to their own businesses. (Fan)

However, some participants found that their exercise of the legitimate pedagogical authority, student-centred approaches, was thwarted by their inability to manage effectively the 'very active' and 'participatory' students in the cross-cultural teaching contexts.

They often ask a lot of questions, so sometimes a planned 15-minute activity would take around half an hour to finish because they have so many questions. (Yan)

Maybe activities are not good for those students. The first time I tried activities, the whole class was like a circus. The students were over-excited... Thus the activity turned out to be turmoil. (Jing)

Frustrated by the chaos and loss of control due to their limited ability to manage the cross-cultural students during student-centred activities, some participants ended up reverting back to primarily traditional approaches to teaching with occasional use of student-centred activities so as to manage the class more effectively. However, their perception of their inability to control students might be shaped by their culturally embedded notion of acceptable noise level in the classroom. Li reported being initially very unsatisfied with her implementation of student-centred activities since she felt that the students were very noisy and out of control. However, her mentor reminded her to look deeper into the nature of student noise and distinguish 'meaningful noise' from the meaningless one. Li felt that her mentor helped elevate her 'tolerance of noise', and affirmed her perception of student-centred approaches as legitimate pedagogical authority.

\section{Changing perceptions of legitimate interpersonal authority}

Prior to the school experience, when asked what kind of relationships they wanted to build with the students, all the participants expressed the wish to build friendly relationships with the students.

I expect to become friends with the students, or like their big sisters. That kind of relationship is very relaxing, not fearful nor coercive. Equal relationship is better. (Fen)

I want to befriend students. No rigid power distance. Teachers can guide students but in the role of friends. You don't need to be authoritarian with the students. Just reason with them, and they'll understand. (Fan) 
They did not like the traditional student-teacher relationships where there is a clear line between teachers and students. They felt that 'that kind of relationships set teachers and students on the opposite sides'. But at the same time, the participants expected themselves to be the 'giver' in this friendship relation. They believed that legitimate teacher authority could be established through the teacher acting as a wise adult friend who intends well, impresses students with strong disciplinary knowledge and skills, and proves useful to the students:

When students see your good intentions and understand you are doing things with their best interests in mind, your authority will naturally be built up. (Fan)

If students feel that they can learn from you whatever they want to learn, they will admire you. (Yang)

If you let students feel that you can help them and are right most of the time, they will come to you to seek knowledge and solutions to problems. (Ping)

After observing the various discipline problems and the interactions between their mentors and the students at the school attachment phase, the participants came 20 to realise that the friendship needs to be built on a more equal basis. Namely, legitimate interpersonal authority could only be asserted through treating students as equals, maintaining mutual respect and caring for each other:

The students in the international schools care a lot about whether you show interest in their personal lives. The small chitchat over the students' personal lives, such as talking about their birthday gifts, helped the teacher to win students' hearts and respect. (Mei)

The students in the international schools expect close relationships with their teachers. They don't treat you as an authority, but they show their sincere care for you. (Qi)

The participants found that when their mentor teachers treated their students as 30 equals and trusted students' self-discipline, legitimate teacher authority was more effectively asserted. For instance, Fen shared her mentor's successful practice in asserting legitimate teacher authority to resolve the problem of students failing to submit homework. Her mentor did not lose his temper or impose any punishment when one student failed to submit homework more than three times. He simply asked the student to write up and sign a contract of homework submission deadlines and hang the contract on the wall as a reminder. Fen found that this strategy of trusting students as equals, responsible beings helped the mentor teacher to assert legitimate teacher authority. Other participants also found that this kind of equal relationship helped their mentor teachers gain students' trust and respect:

The teacher often treated his students as equal partners when discussing issues. He cautioned students not to follow others' views blindly. He made the students feel that they could trust him and engage in conversations with him on an equal basis. (Ping)

I like the teaching style of the female teacher. She liked to joke with the students, making the class atmosphere very alive. Students liked to chat with her on many topics and treated her as a family member. (Xuan)

However, during the main teaching practice phase, the participants found that their intention to build equal, close relationships with the students did not establish legitimate teacher authority as they had expected. They found that when they treated the students as equals, 'the students did not treat [them] as teachers', 'would not listen to [them]' and 'abused [their] good intention to be nice'. Furthermore, they 


\section{C. Lai et al.}

found that students responded differently to their efforts to create equal relationships with the students: 'some students appreciated you for treating them as equals, while others would think you were easy to manipulate and would try to gain the upper hand'. Such experiences made the participants change their priority from building equal and close relationships with the students to stressing the importance of authoritarian practices:

I feel that the teacher-student relationship needs to be serious and strict first and then gradually loosen up. You need to establish your authority first and let them obey the rules you set. If you were nice to them from the right beginning, like friends, they wouldn't listen to you. (Ming)

Nonetheless, quite a few participants expressed frustration over their limited ability to maintain the delicate balance between close relationship and strict governance. They felt it was 'hard to find the right balance' and found themselves struggling with "when to use "soft" tactics and when to use "tough" ones'. They attributed this limitation to their lack of cultural knowledge and skills and found that some commonly employed approaches in their own culture might not work well in the new cross-cultural teaching contexts. For instance, Juan and Wen discovered that using the usual approach of encouraging students to study seriously by setting up longterm goals did not work with the students. Jun was reminded by her mentor not to use negative words, such as 'not capable', 'lagging behind' and so on, when interacting with the students. Ping and Fen found that getting angry with students could not help them control the situation; on the contrary, it made the situation worse. The participants also dared not use some common discipline approaches due to the lack of cultural information. Xuan observed that some students sometimes kept their earphones on during the class and refused to take them off despite her repeated reminders. She felt puzzled about how to deal with such situations since, in her words, 'you can't force them'. Jing also reflected: 'I am used to reasoning with or chiding students when they misbehave. However, I dare not use this approach here. I don't know how to deal with students' misbehaviour'. She further pointed out that this hesitancy came from her lack of knowledge of how to discipline students from different cultures:

If I'm dealing with Chinese students, I know how to control them because I know their weak points. It's relatively easy to handle since I know them well, whereas when I'm facing these students from international schools, it's hard. I don't even know how to respond in appropriate language and in an appropriate manner, to say nothing of building relationships with them. (Jing)

Similar feelings of a lack of appropriate cultural information to build up positive student-teacher relationship were echoed by other participants as well:

Now I feel quite at a loss. The school is dominated by their culture and their way. We are like foreigners who try to enter their world. We have first of all to follow their rules. However, there are so many things we don't know and understand. (Xin)

When students misbehaved, I dared not discipline them in my way. I was extremely worried that my method of discipline might incur their complaints. (Yan) 


\section{Discussion}

This study examined a group of pre-service Chinese-language teachers' changing perceptions of legitimate teacher authority during their teaching practicum at international schools in Hong Kong. It found that the pre-service teachers' understanding of legitimate pedagogical and interpersonal authority was constantly reshaped. Not only did their perceptions of the relative importance of pedagogical and interper-

10 sonal authority in gaining legitimacy in the cross-cultural teaching contexts change, but their perceptions of what legitimate pedagogical and interpersonal authority in the teaching contexts entail went through reconstruction as well. More importantly, the reconstruction process was shaped by both a heightened awareness of the sociocultural realities of the cross-cultural teaching contexts and the pre-service teachers'

15 knowledge and skills in dealing with pedagogical and interpersonal relationships in the cross-cultural teaching contexts.

Concurring with previous literature (Elliot and Stemler 2008; Pace and Hemmings 2007; Roberson 2014), this study found that legitimate teacher authority relies on culturally appropriate pedagogical and interpersonal authority and the positive 20 interaction between the two. In the cross-cultural teaching contexts, the interdependence of pedagogical authority and interpersonal authority was even more pronounced. The pre-service Chinese-language teachers in this research found that student-centred pedagogies that respect students' characteristics, interests and preferences were the appropriate pedagogy that could help them gain legitimacy in their Western ideology-dominated cross-cultural teaching contexts. However, the participants' limited knowledge and skills in handling the interpersonal dynamics during student-centred activities in the cross cultural teaching contexts imposed difficulties for gaining legitimate pedagogical authority. Thus, the link between pedagogies and the interpersonal dynamics involved needs to be highlighted in the training of any 30 pedagogical approaches.

In the case of preparing teachers for cross-cultural teaching, the training of any pedagogical approaches needs to focus not only on the fundamentals of the approaches, but more importantly on the culturally appropriate implementation strategies, such as culturally responsive classroom and time management techniques, culturally effective written or oral communication strategies, and so on. In this study, the participants' concerns over losing control of the class during student-centred activities resulted in some of them reverting back to relying primarily on didactic teaching. What was at work here might not just be a lack of cultural knowledge and skills on interpersonal dynamics, but also different cultural connotations and beliefs about what 'discipline' and 'learning' mean and look like. Thus throwing pre-service teachers into cross-cultural teaching practicum without preparing them well for the different cultural connotations of discipline and learning and for the culturally appropriate strategies in building positive pedagogical relationships runs the risk of reinforcing their stereotypes of international students and beliefs about the need for 45 pedagogies that give them tighter control of the class.

The pre-service teachers examined here shifted from a predominant emphasis on pedagogical authority to a heightened awareness of the importance of interpersonal authority, and from an overreliance on a permissive and accommodating approach to the realisation of a balanced approach to student-teacher relationship. This shift 50 towards a balanced view is a positive development, as such a balance is critical to legitimate teacher authority (Elliott 2009; Pellegrino 2010; Roberson 2014). How- 
ever, these pre-service teachers' efforts to build a balanced, positive student-teacher relationship in the cross-cultural teaching contexts were thwarted by their lack of cultural knowledge and skills. Thus, the social aspect of teacher authority needs to be highlighted in initial teacher training and it is critical in providing pre-service teachers with support in establishing culturally appropriate student-teacher relationships (Hu 2014). Pre-service teachers need to be informed of the cultural norms concerning student-teacher relationships in the new teaching contexts and given explicit opportunities to construct a new contextually situated professional identity (Nguyen 2008; Scotland 2014). They need to be guided to use the effective approaches that teachers adopt to establish interpersonal authority among students. It is important to give pre-service teachers opportunities to observe the diversity of teaching styles of mentor teachers of both Western and Eastern backgrounds so that they can be given sufficient models to form their unique style of teacher authority. Pellegrino (2010) pointed out that pre-service teachers need to be supported in developing not only charismatic authority, but also culturally- and age-appropriate legal/rational authority since sole reliance on charismatic authority often leads to chaotic behaviour in preservice teachers' classrooms and makes teachers revert to authoritarian practices. This study found the same phenomenon. It further revealed that cultural barriers made it hard for the pre-service teachers to assert coercive authority and authority by inducement since the techniques that had worked in their own cultures may be deemed inappropriate in cross-cultural contexts. Their lack of knowledge of culturally appropriate coercive and inducement measures made them struggle during the main teaching practice phase. It is thus important to equip pre-service teachers with such information and guide them to discuss and reflect on effective coercive and inducement techniques that teachers in such teaching contexts utilise to assert bureaucratic authority.

Furthermore, this research found that the pre-service teachers' perceptions of legitimate teacher authority in the particular cross-cultural teaching contexts changed significantly in the eight-week school attachment phase. This prolonged period of time of observation from a third-person perspective helped them to realise the importance of interpersonal authority and the pedagogical authority that was appropriate to the students, and gave them opportunities to observe different techniques to assert these two types of authority from their mentors in the unfamiliar cross-cultural teaching contexts. The class observation phase of the school teaching practicum might have served as a buffer zone to help the pre-service teachers to see the big picture and not to be bogged down by the details of teaching right from the beginning. Thus, taking a gradual induction approach that allows pre-service teachers to observe school practices and get familiar with the sociocultural realities at the schools is critical to smoothing the pre-service teachers transition to the cross-cultural teaching contexts. Furthermore, at such a phase, students need to be guided to focus specifically on how legitimate pedagogical authority and interpersonal authority are defined in the cross-cultural teaching contexts and on mentor teachers' strategies and techniques in asserting legitimate pedagogical and interpersonal authorities in these contexts.

\section{Conclusion}

The current research literature identifies various challenges that immigrant teachers have encountered in asserting legitimate teacher authority in cross-cultural teaching 
contexts. This study reported on how a group of pre-service Chinese teachers from mainland China, facing these challenges, developed understanding of legitimate teacher authority in their cross-cultural teaching contexts during teaching practicum, and how their perception of legitimate teacher authority changed in response to their understanding of the sociocultural realities at the teaching contexts and their grasp of relevant culturally appropriate pedagogical and interpersonal skills. This investigation found that these pre-service teachers were, in general, developing a more nuanced and balanced understanding about legitimate teacher authority over time. However, their abilities in reaching the balance were constrained by their cultural knowledge and skills and their abilities in achieving positive interpersonal dynamics when implementing student-centred pedagogies. This research contributes to our

15 understanding of teachers' developing understanding of legitimate teacher authority in different contexts and the factors that shape the development (Graca, Calheiros, and Barata 2013; Pace and Hemmings 2007; Roberson 2014) and calls for teacher training programmes to develop pre-service teachers' understandings of, and abilities to, exert culturally appropriate pedagogical and interpersonal authority in cross-cul20 tural teaching contexts since such knowledge does not come automatically with experience (Thomas and Beauchamp 2011). Although the findings are based on the accounts of a group of pre-service Chinese-language teachers in cross-cultural teaching contexts, the struggle to reconcile the gap between their own behavioural inclinations and those required by their teaching practicum placement contexts and 25 so come to terms with the sociocultural realities of the teaching contexts may well hold true for all student teachers. Thus, some supporting mechanisms suggested out of this study may apply equally to all pre-service teacher training programmes to help smooth the transition of student teachers into the teaching professions.

This survey presents a group of Chinese language per-service teachers' changing 30 perception of legitimate teacher authority when engaged in teaching practice in school contexts dominated by Western cultures. The trajectories and challenges might be very different in different cross-cultural teaching situations and for pre-service teacher training programmes with different teaching practicum arrangements. It would be worthwhile examining the issue of pre-service teachers learning to assert 35 legitimate teacher authority in different contexts. Moreover, in this study, no formal support mechanisms, in addition to the informal dialogues and sharing among the pre-service teachers when they met for the evening classes, were built into the programme to provide affective and cognitive support to help the pre-service teachers come to terms with their varying experiences at their teaching practicum sites. It 40 would be interesting to examine the effects of different formal and informal support mechanisms on pre-service teachers' development of legitimate teacher authority and to compare the relative efficacies of these support mechanisms on pre-service teachers of different cultural backgrounds. The particularities of the participants (all female teachers teaching Chinese language undertaking a practicum at the secondary 45 school level) limit the generalisability of the research findings, since gender and the socially imposed value of a particular subject may affect the degree and nature of the challenges encountered by pre-service in asserting legitimate teacher authority. More research is needed to examine how pre-service teachers of different gender and of subjects with different socially imposed values develop legitimate teacher 50 authority in different cross-cultural teaching situations. Moreover, this study was solely based on pre-service teachers' self-reported perception data. What is reported might be different from what is enacted in the classroom. Future studies may well 
want to examine pre-service teachers' negotiation and enactment of legitimate teacher authority in the cross-cultural classrooms to enrich our understanding of the phenomenon.

\section{Disclosure statement}

No potential conflict of interest was reported by the authors.

\section{References}

Beauchamp, C., and L. Thomas. 2009. "Preparing Prospective Teachers for a Context of Change: Reconsidering the Role of Teacher Education in the Development of Identity." Cambridge Journal of Education 39 (2): 175-189.

Bogdan, R. C., and S. K. Biklen. 2003. Qualitative Research for Education: An Introduction to Theories and Methods. 4th ed. New York: Pearson Education Group.

Coldron, J., and R. Smith. 1999. "Active Location in Teachers' Construction of their Professional Identities." Journal of Curriculum Studies 31 (6): 711-726.

Elliott, J. G. 2009. "The Nature of Teacher Authority and Teacher Expertise." Support for Learning 24: 197-203.

Elliott, J. G., S. E. Stemler, R. J. Sternberg, E. L. Grigorenko, and N. Hoffman. 2011. "The Socially Skilled Teacher and the Development of Tacit Knowledge." British Educational Research Journal 37: 83-103.

Gao, Y. 2010. "A Tale of Two Teachers: Chinese Immigrant Teachers' Professional Identity in US Foreign Language Classrooms." Unpublished doctoral diss., University of Minnesota, Minneapolis.

Giroux, H. A., and P. McLaren. 1986. "Teacher Education and the Politics of Engagement: The Case for Democratic Schooling." Harvard Educational Review 56 (3): 213-239.

Graca, J., M. M. Calheiros, and M. C. Barata. 2013. "Authority in the Classroom: Adolescent Autonomy, Autonomy Support, and Teachers' Legitimacy." European Journal of Psychology Education 28: 1065-1076.

Haley, M. H., and M. S. Ferro. 2011. "Understanding the Perceptions of Arabic and Chinese Teachers toward Transitioning into U.S. Schools." Foreign Language Annals 44 (2): 289-307.

Hanson, E. C. 2013. “"To Know the System and Know the Culture is Difficult': Understanding the Cultural Adjustment Process of Teachers from China Working in U.S. K-12 Schools." Unpublished master's thesis, The University of Minnesota, Minneapolis.

Harjunen, E. 2011. "Students' Consent to a Teacher's Pedagogical Authority." Scandinavian Journal of Educational Research 55: 403-424.

Hearn, J. 2012. Theorizing Power. Basingsoke: Palgrave Macmillan.

HKED (Hong Kong Education Department). 1995. Report of the Working Group on the Provision of International School Places. Hong Kong. http://www.edb.gov.hk/FileMan ager/TC/Content 689/intl e.pdf.

Izadinia, M. 2013. “'A Review of Research on Student Teachers' Professional Identity.” British Educational Research Journal 39 (4): 694-713.

Kim, J. 1998. "Korean Children's Concepts of Adult and Peer Authority and Moral Reasoning." Developmental Psychology 34: 947-955.

Koutrouba, K., E. Baxevanou, and A. Koutroumpas. 2012. "High School Students' Perceptions of Attitudes towards Teacher Power in the Classroom." International Education Studies 5 (5): 185-198.

Lai, C. 2013. "A Framework of Developing Self-directed Technology use for Language Learning." Language Learning \& Technology 17 (2): 100-122.

Laupa, M., and P. Tse. 2005. "Authority Concepts among Children and Adolescents in the Island of Macao." Social Development 14: 652-663.

Li, T. 2012. "Comparison of American and Chinese College Students' Perception of Instructor Authority." Journal of International Students 2 (1): 116-122. 
Liu, X. 2012. Becoming Laoshi in US High Schools: Case Studies of Three Foreign-born Chinese Language Teacher Candidates. Unpublished doctoral diss., The University of Maryland, College Park.

Macleod, G., J. MacAllister, and A. Pirrie. 2012. "Towards a Broader Understanding of Authority in Student-Teacher Relationships." Oxford Review of Education 38 (4): 493508.

10 McCluskey, K. 2012. "The Absolute Necessity for a Working Model to Support Pre-service Teachers of a Non-English Speaking Background." Journal of Education for Teaching: International Research and Pedagogy 38 (5): 571-584.

Nathan, D. B. 2012. "Negotiating Authority through Jointly Constructing the Course Curriculum." Teachers and Teaching 18: 159-180.

15 Nguyen, H. T. 2008. "Conceptions of Teaching by Five Vietnamese American Preservice Teachers." Journal of Language, Identity \& Education 7 (2): 113-136.

Oyler, C. 1996. Making Room for Students. New York: Teachers College.

Pace, J. L., and A. Hemmings. 2007. "Understanding Authority in Classrooms: A Review of Theory, Ideology, and Research." Review of Educational Research 77 (1): 4-27.

20 Pellegrino, A. M. 2010. "Pre-service Teachers and Classroom Authority." American Secondary Education 38 (3): 62-78.

Pillen, M., D. Beijaard, and P. Brok. 2013. “Tensions in Beginning Teachers' Professional Identity Development, Accompanying Feelings and Coping Strategies." European Journal of Teacher Education 36 (3): 240-260.

25 Richmond, V. P., and J. C. McCroskey. 1984. "Power in the Classroom II: Power and Learning." Communication Education 33 (2): 125-136.

Roberson, R. R. 2014. Understanding the Development of Legitimate Teacher Authority through the Teacher-Student Relationship: A Qualitative Study. Unpublished doctoral diss., Oklahoma: University of Oklahoma.

30 Romig, N. 2009. Acculturation of Four Chinese Teachers Teaching in the United States: An Ethnographic Study. Unpublished doctoral diss., Michigan State University, Michigan.

Sachs, J. 2005. "Teacher Education and the Development of Professional Identity: Learning to be a Teacher." In Connecting Policy and Practice: Challenges for Teaching and Learning in Schools and Universities, edited by P. Denicolo and M. Kompf, 5-21. Oxford: Routledge.

Scotland, J. 2014. "Operating in Global Educational Contact Zones: How Pedagogical Adaptation to Local Contexts may Result in the Renegotiation of the Professional Identities of English Language Teachers." Teaching and Teacher Education 37: 33-43.

Smith, M. P., and E. Matusov. 2011. "A Proposal for a New Schooling: Reciprocity and Authentic Dialogue." Mind, Culture and Activity 18: 297-300.

Subedi, B. 2008. "Contesting Racialization: Asian Immigrant Teachers' Critiques and Claims of Teacher Authenticity." Race Ethnicity and Education 11 (1): 57-70.

Thomas, L., and C. Beauchamp. 2011. "Understanding New Teachers' Professional Identities through Metaphor." Teaching and Teacher Education 27: 762-769.

Trent, J. 2010. "From Rigid Dichotomy to Measured Contingency. Hong Kong Preservice Teachers' Discursive Construction of Identity." Teaching and Teacher Education 26: 906-913.

Wong, M. Y. 2014. Teacher-Student Power Relations as a Reflection of Multileveled Intertwined Interactions. British Journal of Sociology of Education. Advanced online publishing. doi: 10.1080/01425692.2014.916600.

Woo, D. 2014. "Neoliberalism in Two Hong Kong School Categories." Current Issues in Comparative Education 16 (1): 37-48.

$\mathrm{Xu}$, H. 2012. "Challenges Native Chinese Teachers Face in Teaching Chinese as a Foreign Language to Non-native Chinese Students in U.S. Classrooms." Theses, Student Research and Creative Activity: Department of Teaching, Learning and Teacher Education. Paper 20. http://digitalcommons.unl.edu/teachlearnstudent/20.

Zhou, W. Y. 2014. "Chinese Sojourn Teachers' Perceptions of and Experiences with K-12 U.S. Students: Implications for Cross-cultural Classroom Management." In Language Teachers and Teaching: Global Perspectives, Local Initiatives, edited by S. Ben Said and L. Zhang, 288-302. New York: Routledge.Appendix 1. 


\section{Appendix 1. Interview guide}

\section{Interview guide prior to school experience}

(1) What do you think of teaching? What roles should the teacher play?

(2) What is a successful language class like?

(3) What is a successful teacher like?

(4) What do you think student-teacher relationships should be like? What kind of teacher do you want to become?

(5) To become the successful teacher in your mind, what do you need to strengthen the most?

\section{Interview Guide after the School Attachment}

(1) Could you describe your experience at your teaching practicum site in the past few weeks?

(2) What do you think are the roles of the teachers? What is a successful teacher like? Did your opinions on characteristics of successful teacher change in the past few weeks?

(3) What kind of teacher do you want to become? Did your opinions on student-teacher relationships change in the past few weeks? In what way?

(4) What is your teaching philosophy? What is a successful language class like?

(5) What is the biggest impact of school attachment on your perceptions of teaching and being a teacher?

\section{Interview guide after the main teaching period}

(1) Could you describe your experience at your teaching practicum site in the past few weeks?

(2) What is the biggest impact of the main teaching experience on your perceptions of teaching and being a teacher?

(3) What do you think are the roles of the teachers? What is a successful teacher like? Did your opinions on characteristics of successful teacher change in the past few weeks?

(4) What kind of teacher do you want to become? Did your opinions on student-teacher relationships change in the past few weeks? In what way?

(5) What is your teaching philosophy? What is a successful language class like? 